\title{
Malignant paraganglioma of the posterior mediastinum: A case report with genetic analysis
}

\author{
YASUSHI ADACHI ${ }^{1}$, HIROAKI MITA ${ }^{1}$, YASUSHI SASAKI ${ }^{3}$, RYOGO HIMORI ${ }^{1}$, \\ KEI ONODERA ${ }^{4}$, MASAHIRO NAKAMURA ${ }^{1}$, TAKEFUMI KIKUCHI ${ }^{1}$, KENTARO YAMASHITA ${ }^{4}$, \\ YUKINARI YOSHIDA $^{1}$, YOSHIFUMI ISHII ${ }^{2}$ and TAKAO ENDO ${ }^{1}$ \\ ${ }^{1}$ Division of Gastroenterology, Department of Internal Medicine, Sapporo Shirakaba-dai Hospital; \\ ${ }^{2}$ Department of Pathology, Sapporo Shirakaba-dai Hospital, Sapporo, Hokkaido 062-0052; ${ }^{3}$ Department of Medical \\ Genome Sciences, Research Institute for Frontier Medicine, Sapporo Medical University, Sapporo, Hokkaido 060-8556; \\ ${ }^{4}$ Department of Gastroenterology, Sapporo Medical University, Sapporo, Hokkaido 060-8543, Japan
}

Received June 7, 2018; Accepted September 21, 2018

DOI: $10.3892 / \mathrm{mco} .2018 .1758$

\begin{abstract}
Paraganglioma and pheochromocytoma are rare neuroendocrine neoplasms that originate from chromaffin cells. In many of these tumors, several mutations are reported to occur in the genes of germline and/or somatic cells. A case of paraganglioma in the posterior mediastinum with highly malignant potential is reported. The patient had a rapid clinical course, and it was difficult to reach the final diagnosis. The initial diagnosis on fine-needle aspiration biopsy was a gastrointestinal stromal tumor (GIST) arising from the esophagus. Although radiation therapy was effective for the main tumor, the lung metastases did not respond sufficiently to several tyrosine kinase inhibitors. Autopsy and immunohistochemical examination using a battery of different markers resulted in a final diagnosis of malignant paraganglioma. Next-generation sequencing revealed several gene mutations and copy number variations, including of fumarate hydratase $(F H)$, neurofibromatosis type-1 (NFI) and RET. Those gene alterations may contribute to the pathogenesis of this malignant phenotype to a certain extent. To confirm this, further cases and studies are required. In addition, it should be noted
\end{abstract}

Correspondence to: Dr Yasushi Adachi, Division of Gastroenterology, Department of Internal Medicine, Sapporo Shirakaba-dai Hospital, 2-18 Tsukisamu-Higashi, Toyohira-ku, Sapporo, Hokkaido 062-0052, Japan

E-mail: yadachi@sapmed.ac.jp

Abbreviations: CEA, carcinoembryonic antigen; $\mathrm{CNV}$, copy number variation; CT, computed tomography; FFPE, formalin-fixed, paraffin-embedded; FH, fumarate hydratase; GIST, gastrointestinal stromal tumor; MRI, magnetic resonance imaging; NF1, neurofibromatosis type-1; NSE, neuron specific enolase; PCC, pheochromocytoma; PDGFR $\alpha$, platelet-derived growth factor receptor $\alpha$; PGL, paraganglioma; SDH, succinate dehydrogenase

Key words: gastrointestinal stromal tumor, next-generation sequencing, paraganglioma, posterior mediastinum, RET that histological examination of a small piece of tumor might have sampling bias and could cause misdiagnosis.

\section{Introduction}

Sympathetic paragangliomas (PGL) secreting catecholamines are relatively rare neuroendocrine tumors arising from sympathetic paraganglia and the adrenal medulla (known as pheochromocytoma, PCC) $(1,2)$. These tumors comprise specialized neuroendocrine cells of neural crest origin (chromaffin cells), which form multiple nodular structures surrounded by sustentacular cells called 'zellballen'. This organoid structure is lost during malignant transformation.

One-third of PCC/PGL cases are associated with inherited tumor syndromes, in which mutations have been identified in more than 15 genes, including fumarate hydratase $(F H)$, MEN1, neurofibromatosis type-1 (NF1), RET, succinate dehydrogenase (SDH)A, $S D H B, S D H C$, and $S D H D$ (3). These mutations occur in the genes of germline and/or somatic cells (3-5). In nonfamilial PCC/PGL tumors, $41 \%$ harbored mutations and one-fifth were in germline genes, including multiple mutations (6). The major genetic abnormalities of PCC/PGL have been divided into two major categories, such as the pseudohypoxia-driven tumor and the kinase signaling subgroup. Furthermore, a recent paper added two other subgroups, Wnt-altered and cortical admixture subtypes (5). Although the malignant phenotype with metastasis was reported to account for 14 to $50 \%$ of all PCC/PGL cases, it remains difficult to identify $(2,7)$.

Gastrointestinal stromal tumor (GIST) is a relatively rare tumor. The pathogenesis of most GISTs is a mutation in one of two receptor tyrosine kinase genes, kit and platelet-derived growth factor receptor $\alpha$ (PDGFR $\alpha)$ (8). Although PCC/PGL and GIST are uncommon neoplasms that occur mostly in a sporadic and isolated form, they could be components of syndromes, such as neurofibromatosis type 1 and the Carney triad (9).

A case of a rare and aggressive tumor in the posterior mediastinum, which was initially thought to be GIST arising from the esophagus, but was finally diagnosed as malignant 
PGL by immunohistochemistry using a battery of different markers, followed by genomic investigations using semiconductor-based next-generation sequencing, is reported.

\section{Materials and methods}

DNA preparation. This study was approved by the Institutional Review Board of Sapporo Shirakaba-dai Hospital. Formalin-fixed, paraffin-embedded (FFPE) blocks were used for targeted sequencing. To enrich the tumor content, FFPE tumor tissues were subjected to macrodissection. DNA was isolated using the QIAamp DNA FFPE Tissue kit (Qiagen, Hilden, Germany). Normal liver tissue from this case was used as matched non-tumor control. The TaqMan RNase P Detection Reagents kit (Thermo Fisher Scientific, Waltham, MA, USA) was used to quantify purified DNA (10).

Semiconductor-based next-generation sequencing. DNA (40 ng) was used for multiplex PCR amplification with an Ion Ampliseq Comprehensive Cancer Panel, enabling the targeted coverage of all exons of 409 cancer-related genes (Thermo Fisher Scientific). The 15,992 amplicons obtained represented more than 1.69 megabases of target sequence. Library preparation and sequencing with the Ion Torrent sequencer were performed as previously described (10). Somatic mutations (single nucleotide mutations, insertions, and deletions) and copy number variations (CNVs) were detected using statistical approaches in tumor and normal samples from the Ion Reporter software 5.0 tumor-normal workflow (Thermo Fisher Scientific). Recurrent genomic regions with CNVs were identified using copy numbers greater than 3 and less than 1 for gains and losses, respectively. Germline DNA mutations were identified using the Torrent Suite variant caller plugin 5.0 with high-stringency germline parameters and annotated using Ion Reporter.

\section{Case report}

A 44-year-old man was admitted to Sapporo Medical University Hospital with back pain, numbness of the legs, and a gait disturbance. He had a three-year history of hypertension. He was diagnosed with myeloparalysis due to spinal cord compression by an invasive tumor of the posterior mediastinum. After he underwent laminectomy (Th4-6) and posterior interbody fusion (Th4-9), he was treated with steroid pulse therapy. The laboratory findings on admission showed leukocytosis $\left(1,380 \times 10^{6} / 1\right)$ with granulocytosis $\left(1,303 \times 10^{6} / 1\right)$ and hypoalbuminemia $(3.6 \mathrm{mg} / \mathrm{dl})$. Although only two tumor markers were elevated, Cypra at $3.1 \mathrm{ng} / \mathrm{ml}$ and neuron specific enolase (NSE) at $17.3 \mathrm{ng} / \mathrm{ml}$, others were normal, such as carcinoembryonic antigen (CEA) at $0.8 \mathrm{ng} / \mathrm{ml}, \mathrm{CA} 19-9$ at $5.7 \mathrm{U} / \mathrm{ml}$, $\alpha$ fetoprotein at $4 \mathrm{ng} / \mathrm{ml}$, and interleukin-2 receptor at $259 \mathrm{U} / \mathrm{ml}$. Computed tomography (CT) showed a faintly enhanced solid mass, $7 \mathrm{~cm}$ in diameter, that was surrounded by the trachea, aorta, esophagus and thoracic vertebrae (Fig. 1). Magnetic resonance imaging (MRI) showed heterogeneous T2-hyperintense signal tumors invading into 6th and 7th thoracic vertebral column. Since the tumor was located on the left main bronchus, endobronchial ultrasound fine-needle aspiration was performed. Epithelial and spindle-shaped tumor cells showed alveolar growth and were positive for Ki67 (30\%), c-kit, and vimentin, but not for $\alpha$-smooth muscle actin or S100 (Fig. 2, Table I). Thus, he was diagnosed with GIST that probably originated from the esophagus. After receiving radiation ( $40 \mathrm{~Gy} / 16 \mathrm{Fr}$ ) for pain relief, the size of the primary tumor shrank slightly, but multiple lung metastases were detected. Thus, cT3NOM1, stage IV was diagnosed according to UICC 7th. He was treated with $50 \mathrm{mg}$ of sunitinib and then he transferred to Sapporo Shirakaba-dai Hospital. Although the primary tumor was unchanged after 2 courses of sunitinib, the lung metastases were enlarged and there was a bloody pleural effusion that increased (Fig. 3). He was then treated with $400 \mathrm{mg}$ of imatinib, followed by $160 \mathrm{mg}$ of regorabfenib. The tumor, however, progressed clinically and radiologically. The patient died after 8 months, and an autopsy was performed.

The primary mediastinal tumor had shrunk and was not in contact with the esophagus. Necrosis and granulation tissue were seen in the tumor. Multiple metastasized nodules were detected in both lungs. The majority of tumor cells showed rounded, mid-size cells (Fig. 4A-C). There were small amounts of large and pleomorphic cells or mucous cells. Immunohistochemical examination showed that the tumor cells were positive for Ki67 and p53 (Fig. 5, Table I). c-kit was positive in less than $1 \%$ of tumor cells, with no staining for either DOG1 or CD34. NSE was positive, and both synaptophysin and neurofilament were positive in $10 \%$ of the tumor cells, but chromogranin-A was negative. Thus, the diagnosis was malignant paraganglioma with anaplasia. Although tumor cells in low-density nests expressed succinate dehydrogenase (SDH)-B, those in high-density areas did not show much expression (Fig. 5). In addition, histological examination showed bilateral adrenomedullary hyperplasia, which diffusely expanded adrenal medulla and invaded partially into the adrenal cortex (Fig. 4D and E).

Semiconductor-based next-generation sequencing of 409 cancer-related genes showed both germline and somatic mutations and CNVs of genes. Table II shows that germline heterozygous variants in $N F 1$ (p.Gln27His; c. $81 \mathrm{G}>\mathrm{T}$ ) and $R E T$ (p.Asn437Lys: c.1311C $>\mathrm{G}$ ) were found. Moreover, somatic mutations in NF1 (p.Arg1306Gln; c.3917G $>$ A) and $F H$ (p.Ala104Thr; c.310G $>$ A) were identified with frequencies of 29.4 and $28.6 \%$, respectively. CNV analysis using sequencing data detected copy number gains encompassing c-kit, $N F 1$, and $R E T$ and copy number losses encompassing $F H$ and $S D H B$.

\section{Discussion}

First, in the present case it had to be determined whether the neoplasm in question was malignant PGL or GIST. Genetic mutation profiling of this tumor demonstrated that the tumor had either germline or somatic mutations of NF1, RET, and $F H$, but not of SDHs, kit or PDGFRa, suggesting the tumor to be PGL, but not of GIST. The reason why the first biopsied tumor material expressed c-kit might be sampling bias, because PGL could express c-kit in some cases, and the biopsy could have been taken from the highly c-kit expressed area of the tumor. Alternatively, tyrosine kinase inhibitors might eliminate c-kit-expressing cells, resulting in the very low expression of c-kit in the residual neoplastic lesions at the time of autopsy, despite the increased copy number of 
Table I. Antibodies and immunohistchemical staining.

\begin{tabular}{|c|c|c|c|c|c|}
\hline Autopsy & Biopsy & Antibody & Clone & Vender & Dilution \\
\hline++ & ++ & Ki67 & MIB-1 & $\mathrm{D}$ & $1: 100$ \\
\hline++ & N/A & p53 & DO-7 & D & $1: 50$ \\
\hline++ & N/A & Neuron-specific enolase (NSE) & Polyclonal & $\mathrm{N}$ & $1: 1$ \\
\hline+ & ++ & Vimentin & V9 & $\mathrm{D}$ & $1: 1$ \\
\hline+ & ++ & c-kit (CD117) & Polyclonal & $\mathrm{D}$ & $1: 50$ \\
\hline+ & - & Synaptophysin (SP) & $27 \mathrm{G} 12$ & $\mathrm{~L}$ & $1: 50$ \\
\hline+ & N/A & Neurofilament protein (NFP) & $2 \mathrm{~F} 11$ & $\mathrm{D}$ & $1: 50$ \\
\hline+ & N/A & Calretinin & DAK-Calret1 & $\mathrm{D}$ & $1: 25$ \\
\hline+ & N/A & WT1 & WT49 & $\mathrm{L}$ & $1: 40$ \\
\hline- & + & $\mathrm{CD} 34$ & QBEnd10 & $\mathrm{D}$ & $1: 50$ \\
\hline- & - & $\alpha$ smooth muscle actin ( $\alpha \mathrm{SMA})$ & $1 \mathrm{~A} 4$ & $\mathrm{D}$ & $1: 50$ \\
\hline- & - & chromogranin A (CGA) & DAK-A3 & $\mathrm{D}$ & $1: 100$ \\
\hline- & - & Cytokeratin AE1/AE3 & AE1/AE3 & $\mathrm{D}$ & $1: 1$ \\
\hline- & - & Discovered on GIST-1 (DOG1) & K9 & $\mathrm{L}$ & $1: 100$ \\
\hline- & - & Melanoma-associated antigen, HMB45 & HMB45 & $\mathrm{D}$ & $1: 50$ \\
\hline- & - & S100 & S100 & $\mathrm{D}$ & $1: 500$ \\
\hline- & - & SOX10 & Polyclonal & $\mathrm{C}$ & $1: 20$ \\
\hline- & - & Thyroid transcription factor-1 (TTF1) & $8 \mathrm{G} 7 \mathrm{G} 3 / 1$ & $\mathrm{D}$ & $1: 50$ \\
\hline- & - & CD5 & $\mathrm{CD} 5 / 54 / \mathrm{F} 6$ & $\mathrm{D}$ & $1: 50$ \\
\hline- & - & CD10 & $56 C 6$ & $\mathrm{~L}$ & $1: 40$ \\
\hline- & - & CD45 & $2 \mathrm{~B} 11+\mathrm{PD} 7 / 26$ & $\mathrm{D}$ & $1: 1$ \\
\hline- & - & CD56 & $123 \mathrm{C} 3$ & M & $1: 10$ \\
\hline- & N/A & $\alpha$ phetoprotein (AFP) & Polyclonal & $\mathrm{D}$ & $1: 1,000$ \\
\hline- & $\mathrm{N} / \mathrm{A}$ & Carcinoembryonic antigen (CEA) & II-7 & $\mathrm{D}$ & $1: 1,000$ \\
\hline- & N/A & Desmin (Des) & D33 & $\mathrm{D}$ & $1: 50$ \\
\hline- & N/A & Low molecular weight keratin (LMWK) & CAM5.2 & $\mathrm{B}$ & $1: 1$ \\
\hline- & N/A & MDM2 & IF2 & I & $1: 100$ \\
\hline- & N/A & Myogenic differentiation 1 (myoD1) & $5.8 \mathrm{~A}$ & $\mathrm{D}$ & $1: 100$ \\
\hline- & N/A & OCT3 & $\mathrm{C}-10$ & $\mathrm{~S}$ & $1: 100$ \\
\hline- & N/A & Podoplanin & $\mathrm{D} 2-40$ & $\mathrm{D}$ & $1: 50$ \\
\hline- & N/A & Prostate-specific antigen (PSA) & ER-PR8 & $\mathrm{D}$ & $1: 500$ \\
\hline- & N/A & SALL4 & M03 & AN & $1: 400$ \\
\hline- & N/A & Succinate dehydrogenase-B (SDHB) & Polyclonal & AA & $1: 700$ \\
\hline- & N/A & $\mathrm{CD} 3$ & F7.2.38 & $\mathrm{D}$ & $1: 25$ \\
\hline- & N/A & $\mathrm{CD} 20$ & L26 & $\mathrm{D}$ & $1: 200$ \\
\hline- & N/A & $\mathrm{CD} 30$ & Ber-H2 & $\mathrm{D}$ & $1: 25$ \\
\hline- & N/A & CD68 & KP1 & $\mathrm{L}$ & $1: 200$ \\
\hline- & N/A & CD163 & AM-3K & $\mathrm{T}$ & $1: 25$ \\
\hline
\end{tabular}

++, strongly positive; +, weakly positive; -, negative; N/A, not performed; AA, Atlas Antibodies (Bromma, Sweden); AN, Abnova (Taipei, Taiwan); B, Becton Dickinson (Franklin Lakes, NJ); C, Cell Marque/Millipore Sigma (Rocklin, CA); D, Dako (Glostrup, Denmark); I, Invitrogen/Thermo Fisher Scientific (Waltham, MA); L, Leica Biosystems (Newcastle, UK); M, Monosan (Liden, Netherlands); N, Nichirei BioSciences (Tokyo, Japan); S, Santa Cluz Biotechnology (Dallas, TX); T, Trans Genic Inc (Fukuoka, Japan).

kit gene in these lesions. The pulmonary metastasis showed a tiny area of c-kit-positive tumor cells, which occupied less than $1 \%$ of the total tumor areas examined. In addition, although both CD34 and DOG1 have been reported to be expressed highly in GIST (8), but not in PGL, both molecules were not expressed in both biopsied and autopsied tumor samples. This result might support a diagnosis of PGL, not
GIST, for this neoplasm. Furthermore, the tumor cells highly expressed NSE and partially expressed synaptophysin and neurofilament protein, supporting the neuroendocrine origin of the tumor.

The primary mediastinal tumor was $7 \mathrm{~cm}$ in diameter and might have had histological heterogeneity. Since fine-needle aspiration could take only a limited part of the tumor, sampling 

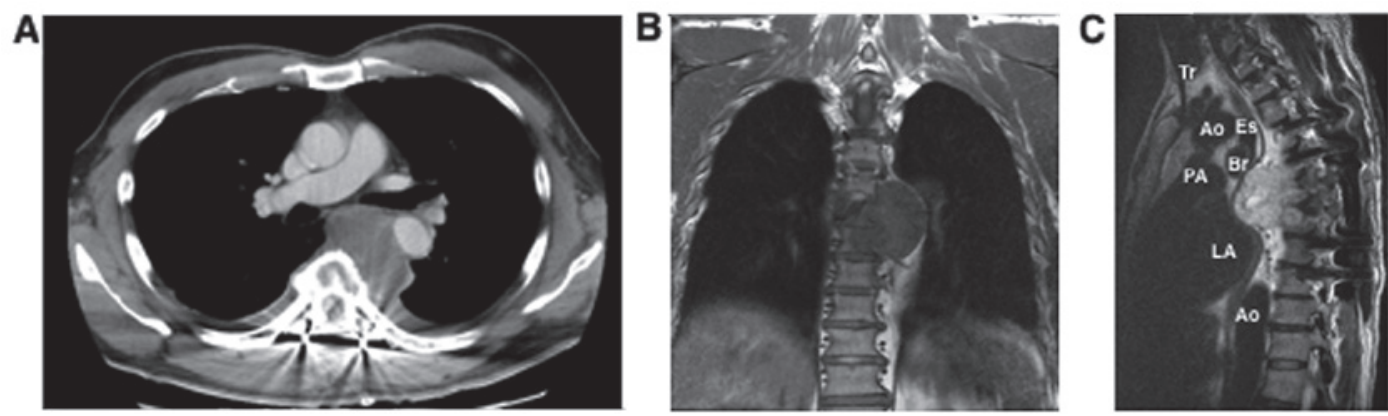

Figure 1. Primary tumor in the posterior mediastinum. (A) Enhanced CT scan showed a faintly enhanced solid mass, which was $7 \mathrm{~cm}$ in diameter and was surrounded by the trachea, aorta and thoracic vertebrae. (B and C) MRI showed heterogeneous T1-hypointesnse and T2-hyperintense signal tumors invaded into 6th and 7th thoracic vertebral columns. Ao, aorta; Br, bronchi; Es, esophagus; LA, left atrium; PA, pulmonary artery; Tr, trachea.

A

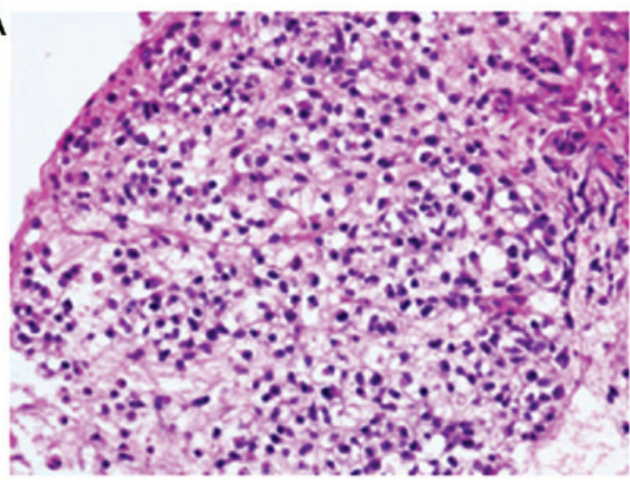

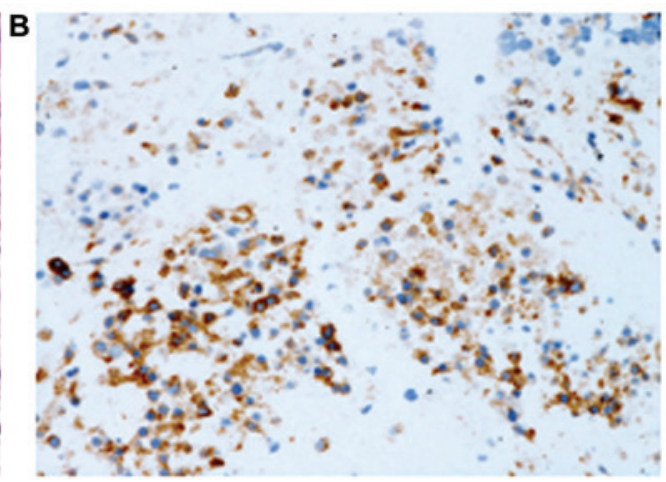

Figure 2. The primary tumor sampled by endobronchial ultrasound fine-needle aspiration. (A) Epithelial and spindle-shaped tumor cells showed alveolar growth solid. (B) Immunohistochemical examination showed positive for c-kit. Magnification, x200.
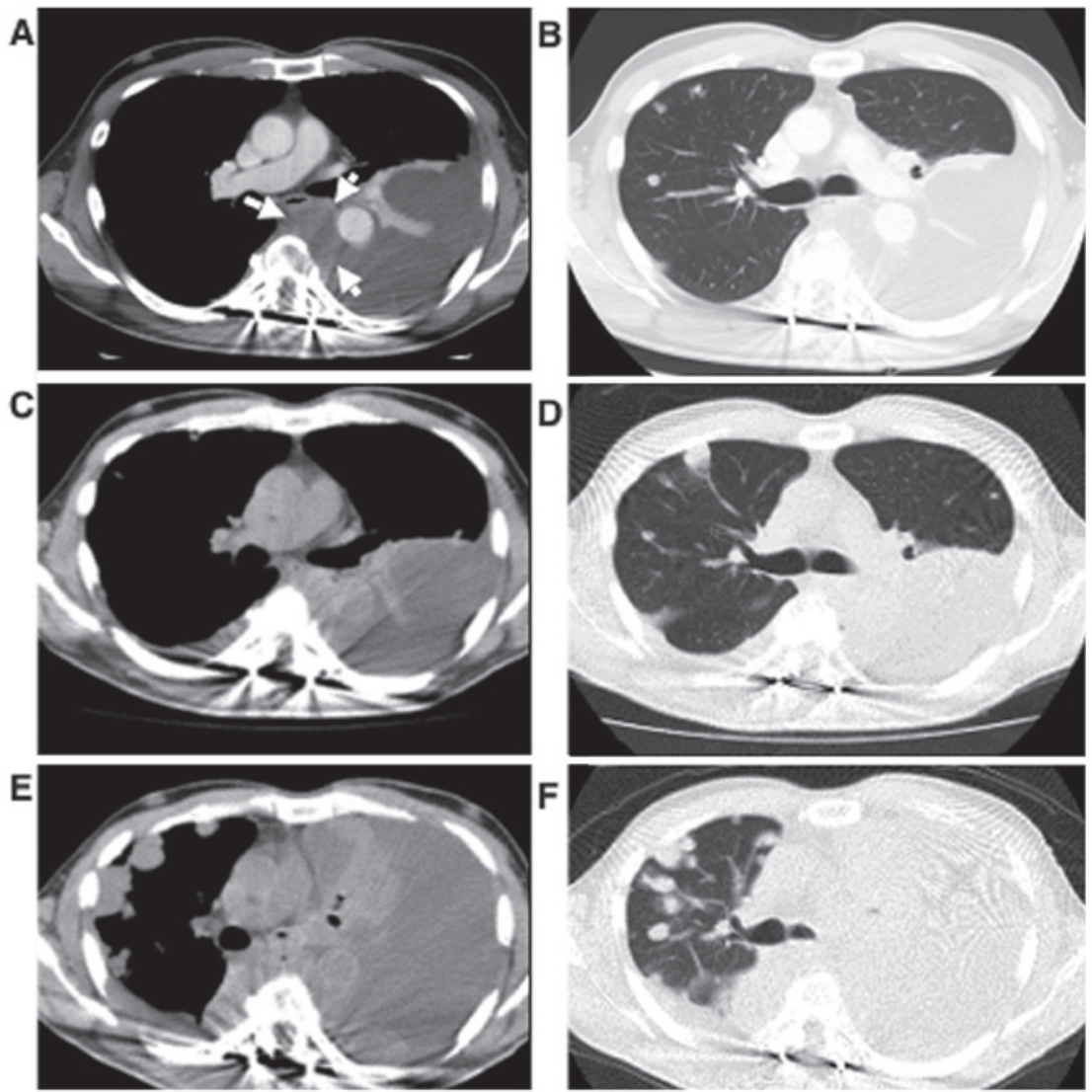

Figure 3. Sequential CT scans showing change in size and numbers of lung metastases but not change in size of the primary tumor (arrow). The volume of bloody pulmonary effusion was increased. (A and B) after radiation; (C and D) after the second course of sunitinib; and (E and F) 2 weeks after imatinib. 
Table II. Summary of gene mutations.

\begin{tabular}{|c|c|c|c|c|c|c|c|c|}
\hline Cell type & Gene & Locus & Mutation type & Protein change & Coding & SIFT & PolyPhen-2 & Grantham \\
\hline \multirow[t]{2}{*}{ Germline } & RET & $\operatorname{chr10:43606702}$ & Missense & p.Asn437Lys & c. $1311 \mathrm{C}>\mathrm{G}$ & 0.02 & 0.171 & 94 \\
\hline & $N F 1$ & $\operatorname{chr17:29483021}$ & Missense & p.Gln27His & c. $81 \mathrm{G}>\mathrm{T}$ & 0.27 & 0 & 24 \\
\hline \multirow[t]{2}{*}{ Somatic } & $N F 1$ & $\operatorname{chr} 17: 29562982$ & Missense & p.Arg1306Gln & c. $3917 \mathrm{G}>\mathrm{A}$ & 0.15 & 0.323 & 43 \\
\hline & $F H$ & $\operatorname{chr} 1: 241676971$ & Missense & p.Ala104Thr & c. $310 \mathrm{G}>\mathrm{A}$ & 0 & 1 & 58 \\
\hline
\end{tabular}

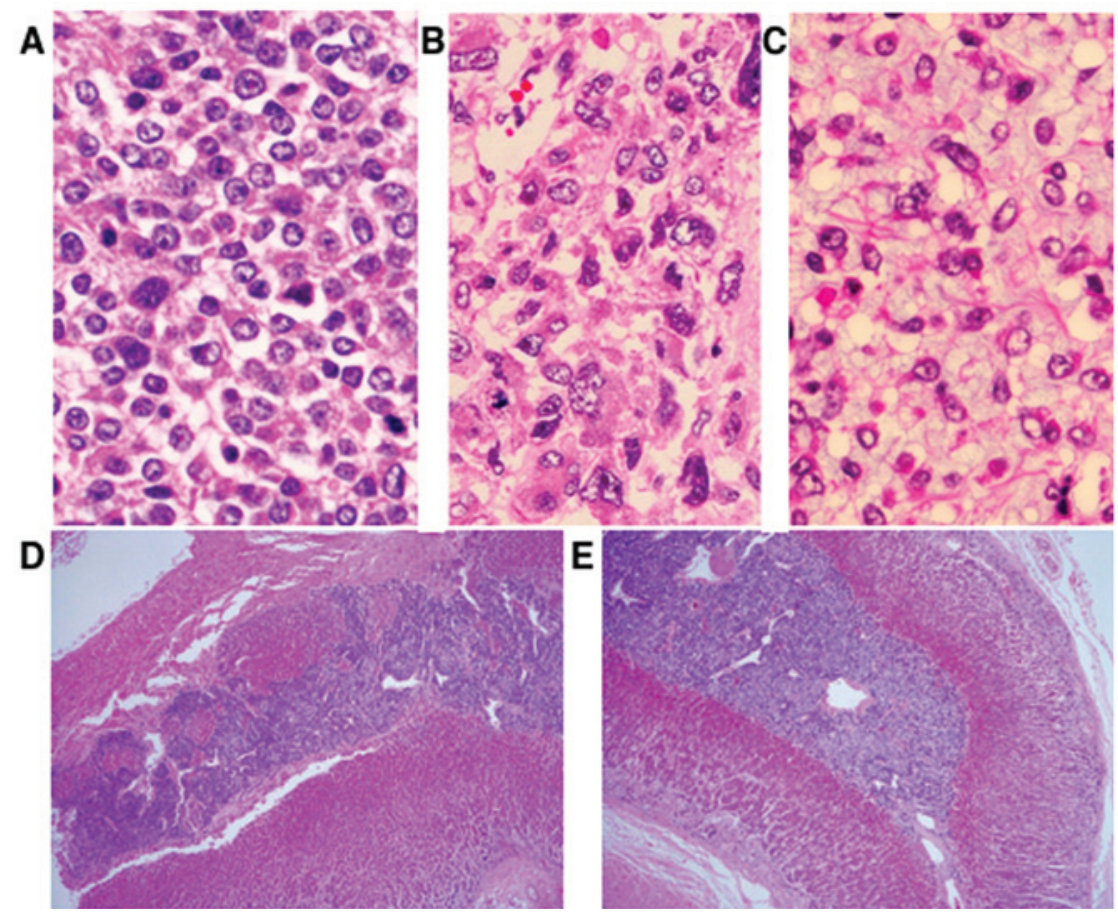

Figure 4. Histological features of metastasized lung tumors (A-C) and adrenal glands (D and E) by autopsy. (A-C) The majority of tumor cells showed a rounded and middle size of cells. There were small amounts of large and pleomorphic cells or mucous cells (magnification, x200). (D and E) Adrenomedullary hyperplasia expanded diffusely (E, right adrenal gland) and invaded into the adrenal cortex (D, left adrenal gland). Magnification, x20.

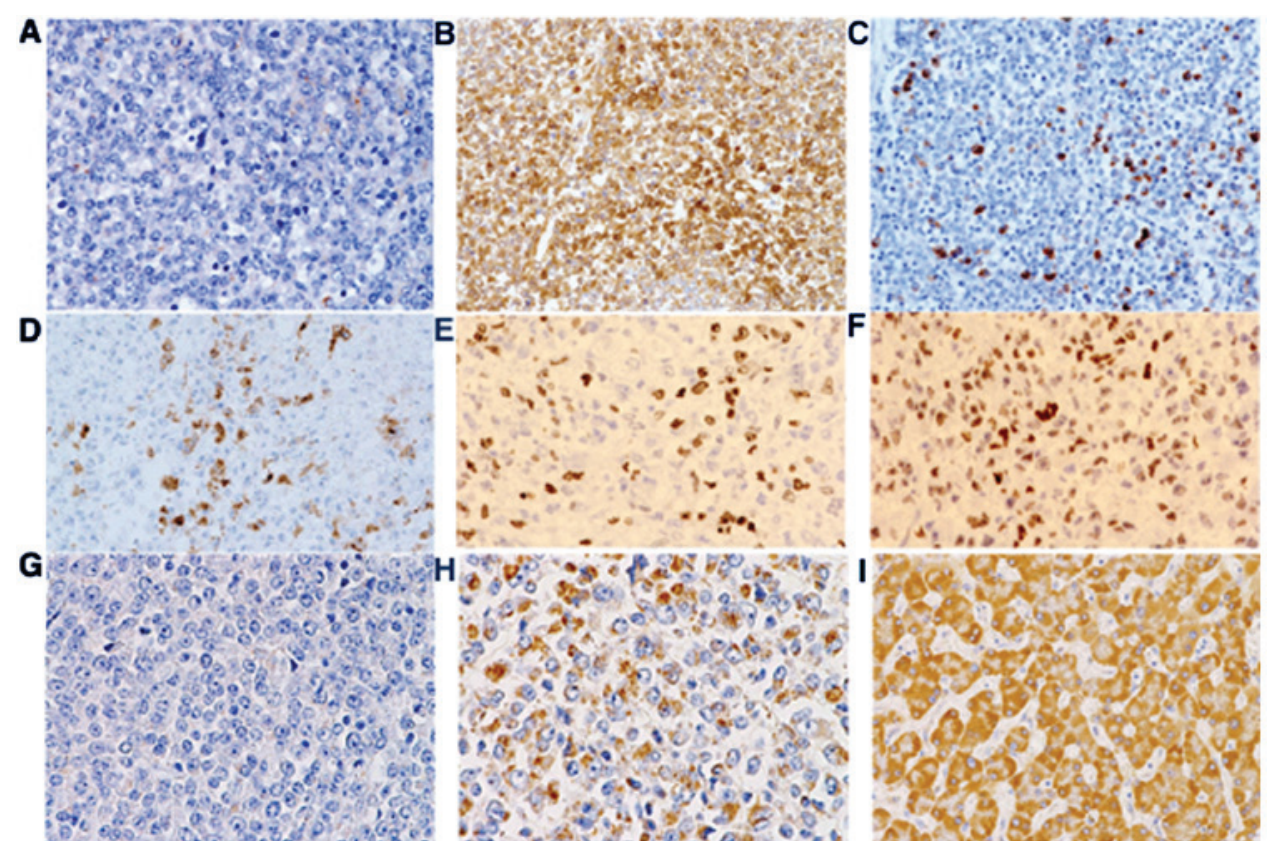

Figure 5. Immunohistochemical features of the metastasized tumors (A-H) and control of liver (I). (A) c-kit, (B) NSE, (C) neurofilament, (D) symaptophysin, (E) ki67, (F) p53 and (G-I) SDHB. Magnification, x200. NSE, neuron specific enolase; SDHB, succinate dehydrogenase B. 
bias might have occurred and led to misdiagnosis. Larger biopsied samples by surgical biopsy or multiple aspiration biopsies might be necessary to make the true diagnosis. In addition, if larger samples had been taken, genetic analysis by next-generation sequencing might have been an option for making the diagnosis.

Highly expressed SDHB in the patient's hepatocytes might indicate that there is no germline mutation of SDH group genes. In addition, genetic studies demonstrated neither germline nor somatic mutations of $S D H s$ in this case. In addition to the reduced number of mitochondria in the tumor cells as compared with the hepatocytes, the reason why the pulmonary metastatic lesions showed reduced expression of SDHB could be due to the micro-environment surrounding the tumor cells, because a high cell density area of the tumor showed reduced SDHB expression but the low cell density area showed high expression in the tumor cells. In addition, the tumor cells around the ischemic coagulation necrosis also showed reduced SDHB expression. It might be possible to assume from these observations that the SDHB expression in the tumor cells would be dependent on the local oxygen content around the tumor cells, since the SDH group enzymes are oxygen-dependent and located within the mitochondria. With the observed reduced copy number of $S D H B$ gene in the tumor cells it is difficult to explain such an uneven expression of SDHB in the tumor areas.

In order to identify causal gene mutations for PCC/PGL without a syndromic presentation, next-generation sequencing might be a promising strategy. Among mutated driver genes for the induction of PGL in the present case, one must consider the possible role of the receptor tyrosine-kinase $R E T$, which showed germline mutation and copy number gain in the tumor cells. Extreme bilateral adrenomedullary hyperplasia, which expanded diffusely in the adrenal medulla and partly invaded into the adrenal cortex, was noted. In this connection, it is noteworthy that the patient had hypertension. These conditions, together with the occurrence of posterior mediastinal PGL, could have been related to the RET abnormalities described. Alternatively, it might be possible to presume that the PGL widely metastasized into lungs might produce some neural growth factors resulting in the bilateral adrenomedullary hyperplasia.

Malignant transformation of this PGL with a poor outcome is intriguing (2). The tumor cells showed high Ki67 labeling and p53 expression and metastasized widely into lungs. The tumor lacked S100-positive sustentacular cells, as consistently observed in benign PGL. Accumulation of multiple gene alterations including $N F 1, R E T$, and $F H$ might be responsible for the malignant transformation of PGL in this case. This might be supported by a report that metastatic phenotype and multiple tumors were significantly more frequent in PGL with FH mutations than in those without (11).

Neurogenic tumors account for around $20 \%$ of all primary neoplasms in the mediastinum. In the mediastinum, PCC/PGL occurs in around $1 \%$ of all tumors $(12,13)$. Similar to the present case, spinal cord compression was caused by PCC/PGL $(14,15)$.

Surgery is a standard therapy for PCC/PGL, and either radiation or combination chemotherapy with cyclophosphamide, vincristine, and dacarbazine is optional $(16,17)$.
Tyrosine kinase inhibitors, such as sunitinib, are an additional option $(18,19)$. In this case, radiation might be effective for the primary mediastinal tumor, but the effect of targeted therapies for c-kit was limited.

In cases of histological examination of a small piece of tumor, one should remember the possibility of sampling bias and misdiagnosis. In order to detect causal gene alterations for PCC/PGL without a syndromic presentation, next-generation sequencing might be a promising approach. In the present case, there were several gene alterations with $\mathrm{CNV}$, such as 'two hits' in the NF1, in both germline and somatic cells, a germline variant in RET, and a somatic mutation in $F H$. They might affect the pathogenesis of this malignant phenotype of PGL. Thus, assessment for these precise effects of each gene alteration will be needed.

\section{Acknowledgements}

Not applicable.

Funding

No funding was received.

\section{Availability of data and materials}

All data generated or analyzed during this study are included in this published article.

\section{Authors' contributions}

YA designed the present study and wrote the manuscript mainly. HM analyzed the clinical and published data. YS analyzed genetic data and critically revised the manuscript. RH, MN, TK and YY were part of the gastrointestinal treatment team that treated the present case in Sapporo Shirakaba-dai Hospital. KO and KY were part of the gastrointestinal treatment team that treated the present case in Sapporo Medical University Hospital. YI analyzed pathological data and critically revised the manuscript. TE designed the present study and critically revised the manuscript.

\section{Ethics approval and consent to participate}

This study was approved by the Institutional Review Board of Sapporo Shirakaba-dai Hospital.

\section{Patient consent for publication}

The patient's family provided consent for publication of the data.

\section{Competing interests}

The authors declare that they have no competing interests.

\section{References}

1. Jochmanova I and Pacak K: Pheochromocytoma: The first metabolic endocrine cancer. Clin Cancer Res 22: 5001-5011, 2016. 
2. Hamidi O, Young WF Jr, Gruber L, Smestad J, Yan Q, Ponce OJ, Prokop L, Murad MH and Bancos I: Outcomes of patients with metastatic phaeochromocytoma and paraganglioma: A systematic review and meta-analysis. Clin Endocrinol (Oxf) 87: 440-450, 2017.

3. Neumann HP, Bausch B, McWhinney SR, Bender BU, Gimm O, Franke G, Schipper J, Klisch J, Altehoefer C, Zerres K, et al: Germ-line mutations in nonsyndromic pheochromocytoma. N Engl J Med 346: 1459-1466, 2002.

4. Currás-Freixes M, Inglada-Pérez L, Mancikova V, Montero-Conde C,Letón R,Comino-MéndezI,Apellániz-RuizM, Sánchez-Barroso L, Aguirre Sánchez-Covisa M, Alcázar V, et al: Recommendations for somatic and germline genetic testing of single pheochromocytoma and paraganglioma based on findings from a series of 329 patients. J Med Genet 52: 647-656, 2015.

5. Fishbein L, Leshchiner I, Walter V, Danilova L, Robertson AG, Johnson AR, Lichtenberg TM, Murray BA, Ghayee HK, Else T, et al: Comprehensive molecular characterization of pheochromocytoma and paraganglioma. Cancer Cell 31: 181-193, 2017.

6. Welander J, Andreasson A, Juhlin CC, Wiseman RW, Backdahl M, Höög A, Larsson C, Gimm O and Söderkvist P: Rare germline mutations identified by targeted next-generation sequencing of susceptibility genes in pheochromocytoma and paraganglioma. J Clin Endocrinol Metab 99: E1352-E1360, 2014

7. Turchini J, Cheung VKY, Tischler AS, De Krijger RR and Gill AJ: Pathology and genetics of phaeochromocytoma and paraganglioma. Histopathology 72: 97-105, 2018.

8. Wong NA: Gastrointestinal stromal tumours-an update for histopathologists. Histopathology 59: 807-821, 2011.

9. Perry CG, Young WF Jr, McWhinney SR, Bei T, Stergiopoulos S, Knudson RA, Ketterling RP, Eng C, Stratakis CA and Carney JA: Functioning paraganglioma and gastrointestinal stromal tumor of the jejunum in three women: Syndrome or coincidence. Am J Surg Pathol 30: 42-49, 2006.

10. Nakagaki T, Tamura M, Kobashi K, Koyama R, Fukushima H, Ohashi T, Idogawa M, Ogi K, Hiratsuka H, Tokino T and Sasaki Y: Profiling cancer-related gene mutations in oral squamous cell carcinoma from Japanese patients by targeted amplicon sequencing. Oncotarget 8: 59113-59122, 2017.

11. Castro-Vega LJ, Buffet A, De Cubas AA, Cascón A, Menara M, Khalifa E, Amar L, Azriel S, Bourdeau I, Chabre O, et al: Germline mutations in $\mathrm{FH}$ confer predisposition to malignant pheochromocytomas and paragangliomas. Hum Mol Genet 23: 2440-2446, 2014.
12. Azarow KS, Pearl RH, Zurcher R, Edwards FH and Cohen AJ: Primary mediastinal masses. A comparison of adult and pediatric populations. J Thorac Cardiovasc Surg 106: 67-72, 1993.

13. Takeda S, Miyoshi S, Minami M and Matsuda H: Intrathoracic neurogenic tumors-50 years' experience in a Japanese institution. Eur J Cardiothorac Surg 26: 807-812, 2004.

14. Reyes MG, Fresco R and Bruetman ME: Mediastinal paraganglioma causing spinal cord compression. J Neurol Neurosurg Psychiatry 40: 276-279, 1977.

15. Moran CA, Suster S, Fishback N and Koss MN: Mediastinal paragangliomas. A clinicopathologic and immunohistochemical study of 16 cases. Cancer 72: 2358-2364, 1993.

16. Garibaldi E, Bresciani S, Panaia R, Delmastro E, Malinverni G and Gabriele P: Hereditary paraganglioma syndrome associated with SDHD gene mutations: A patient with multicentric presentation treated with radiotherapy. Case report. Tumori 97: 214-220, 2011.

17. Baudin E, Habra MA, Deschamps F, Cote G, Dumont F, Cabanillas M, Arfi-Roufe J, Berdelou A, Moon B, Al Ghuzlan A, et al: Therapy of endocrine disease: Treatment of malignant pheochromocytoma and paraganglioma. Eur J Endocrinol 171: R111-R122, 2014.

18. Ayala-Ramirez M, Chougnet CN, Habra MA, Palmer JL, Leboulleux S, Cabanillas ME, Caramella C, Anderson P, Al Ghuzlan A, Waguespack SG, et al: Treatment with sunitinib for patients with progressive metastatic pheochromocytomas and sympathetic paragangliomas. J Clin Endocrinol Metab 97: 4040-4050, 2012.

19. Cassol CA, Winer D, Liu W, Guo M, Ezzat S and Asa SL: Tyrosine kinase receptors as molecular targets in pheochromocytomas and paragangliomas. Mod Pathol 27: 1050-1062, 2014.

This work is licensed under a Creative Commons Attribution-NonCommercial-NoDerivatives 4.0 International (CC BY-NC-ND 4.0) License. 